\title{
Correction to: Comparing energy state and environmental impacts in ostrich and chicken production systems
}

\section{Zeynab Ramedani $^{1} \cdot$ Loghman Alimohammadian $^{1} \cdot$ Kamran Kheiralipour $^{2} \cdot$ Parya Delpisheh $^{1} \cdot$ Zahra Abbasi $^{1}$}

Published online: 5 October 2019

(C) Springer-Verlag GmbH Germany, part of Springer Nature 2019

Correction to: Environmental Science and Pollution Research https://doi.org/10.1007/s11356-019-05972-8

The correct name of the $3^{\text {rd }}$ Author is shown in this paper.

The online version of the original article can be found at https://doi.org/ 10.1007/s11356-019-05972-8

$\triangle$ Zeynab Ramedani

zeynab.ramedani@gmail.com

$\triangle$ Kamran Kheiralipour

k.kheiralipour@ilam.ac.ir; kamrankheiralipour@gmail.com

Loghman Alimohammadian

loghman474@gmail.com

Parya Delpisheh

parya.delpisheh@gmail.com

Zahra Abbasi

zarijon1997@gmail.com

1 Department of Mechanization Engineering, Sonqor Faculty of Agriculture, Razi University, Sonqor, Iran

2 Department of Biosystems Engineering, Faculty of Agriculture,

University of Ilam, Ilam, Iran 